The government has now determined on the construction of a small harbor at Skagen, and of two is
moles, respectively at Hanstholm and Vorupör.

The author concludes that in view of the precariou nature of tidal harbor work, and the instances in which success has been only partial, a departure from established practice is called for. Harbors of refuge
have a limited range of utility, unless in land-locked have a limite
positions.

\section{LESSONS OF THE BALTIMORE FIRE.*} By F. W. Fitzpatricik.

TrN years ago there swept over a portion of Minne sota a combination of forest fire and cyclone that re sulted in the wiping out of several thriving villages and an appalling loss of life, paralleled only by that of the Iroquois Theatre holocaust. That was the
"Hinkley fire." I was in the relief party that went to "Hinkley fire." I was in the relief party that went to of utter desolation that unfolded itself before us that night. The heat had been so intense, and the gale so fierce a one that the effect on the buildings and trees and all about was as if Hades itself had been let loose. Here and there were a few lonesome chimneys left standing; all else was totally co was charred and hardened into an almost pavementnot a vestige of a tree trunk or charred building timber to be found - absolute and complete combustion, annihilation. My first impression of the Baltimore fire brought back that other scene to me. Fire had made almost as clean a sweep in that city, leaving here and almost as clean a sweep in that city, leaving here and
there but the tall fireproof "skyscrapers" that, at a distance-where I first saw the ruins-reminded me much of the sentinel-like chimneys at Hinkley.

of course, I have the utmost sympathy for the bus ness men there who have suffered such terrible losses, and in what follows I have no intention of being heart-
less, but will discuss the case as does a doctor in less, but will discuss the case as does a doctor in a
clinic discuss the "subject" upon whom he is operating clinic discuss the "subject" upon whom he is operating
in a few words, and without dramatic or sentimental embellishments.

Never before have our theories of fireproof construc tion received so severe a test; and that those sky-
scrapers are still standing, and that their structura scrapers are still standing, and that their structura
members that were properly protected are intact, is al members that were properly protected are intact, is al
the vindication the most enthusiastic of us supporter of tile fireproofing theories could hope for.

Something like 150 acres of territory is gutted.

I was able to note the intensity of the heat as in dicated by its action on the metals and brick and stone; and while the wind evidently played some peculiar pranks and made strange twistings, the terrible drafts
created by the fire itself performed some wonderfully created by the fire itself performed some wonderfully acrobatic feats, so to speak, in twisting lines vertically as well as horizontally. In places it would seem as if the blast had passed over three and four-storied buildings to attack the six and seven-storied ones most fiercely, while leaving the former to burn more slowly and sometimes from the top down. Three or four buildings escaped in this manner from absolute destruction; one, the Safe Deposit Company building, a two-
story well-built affair, went scot free. The brickwork and the iron shutters showed really but very little of the effects of the terrific heat that must have been all about it. Some. actions of that fire baffie scientific explanation. In the very case of this Deposit Company building, I can understand how the fire could have swept over it so quickly; and there being nothing about its exterior that would readily ignite, that it should escape; but some distance away stands the old Unitel States Stores building, across the street from the new Custom House. On every side of this build ing its neighbors have been completely gutted, while it stands to all appearances absolutely intact. The glass in the windows is not broken, and the window frames are but blistered, while the shutters inside the closel windows are charred and scorched. Could th heat simply have been intense enough to scorch this
woodwork inside, through the glass, but, unaccom panied by flames, and being influenced by counter currents of air, it left the exterior unmarred? The build ing sufferel some in the upper story by reason of the breaking of the skylights, and fire getting in that way. Then here and there in the streets stands a wooden and near it an iron one twisted into all sorts of shapes. The combustion in the buildings was complete and most searching. Usually after a fre there will be charred bits of floor joists still sticking to the walls, and masses of closely packed goods or papers on the ground, their very density preventing their combus-
tion. But not so here. In most of the buildings burned, particularly along the lines of the most intense fire, there is not a vestige of anything but brick and iron left. One would think that the draft had drawn whatever little residue there migh have been up, and scattered it about in cinders and dust. Charred papers were found miles off. and
whole sheets of tin were carried blocks away. Indeed, whole sheets of tin were carried blocks away. Indeed,
the suction or draft created was so great that many the suction or draft created was so great that many
skylights and iron roofs appeared to have been at first lifted before collapsing. Some of the skylight glass appears to have been broken outward, too, and before fire could have had effect upon it from within. In some buildings the glass from the windows is mainly
within them, and in others it is on the outside and well away from them, again showing that the suction of away from them, again showing that the suction of must have been something tremendous. Then in some buildings there is very little glass to be found; it seems to have disappeared; while about others
found stalactite formations of fused glass, which in dicated the terrific heat there must have been genrated.

At one building, on the sidewalk there had been bulletin board with a sheet of the latest news paste upon it. This was but a trifle scorched around the edges. Nothing was left of the building but a few
little stubs of the walls, but this bulletin board was little stubs of the walls, but this bulletin board was at the corner of intersecting. streets. A cross draft of cold air may have protected it, or may there not have
been created an almost absolute vacuum at certain been created an almost

On another building, where iron and glass and stone were either twisted or fused out of all recognizable shape, a small glass sign stands

gilded letters as bright as new!

At the fiercest of the fire were centered most of the mportant commercial houses. The fire fed on the facthere gaining tremendous peadway and intensity, swept this commercial district virtually out of existence "Slow-burning," "mill-constructed," and all kinds of "bullings, good and bad, went by the board. The fire blast-like stroke, and then what might be called a secondary fire worked horizontally along, and burned attacked by the flercer flames. As the photographs will show, a few stalagmites, as it were, of walls and piers alone mark the site of these buildings-and only the "skyscrapers" stand in anything like structura entity, splendid mon

The Continental Trust building, a fifteen-story structure, one of Baltimore's latest and best buildings, was attacked a little more than half way up its height. You can easily follow the work of the fire in these tal buildings. The most intense blast struck it about the
tenth foor. I found typewriters and other metallic materials in that story absolutely fused into a molten
mather materials in that story absolutely fused into a molten
mass, which means at least $2,800 \mathrm{deg}$. From that point mass, which means at least 2,800 deg. From that point
up the flames were evidently less intense. Similar up the flames were evidently less intense. Similar sequently, and on the other side from that first attack, but they were undoubtedly of slightly less intensity.
Then the fire ate away from the second story upward more slowly, and then downward. Of course, window the floor strips in the concrete, and all the contents the floor strips in the concrete, and all the contents
of this and the other fireproof buildings, were deof this and the other fireproof buildings, were de-
stroyed. Some of the newspapers in their excitement stroyed. Some of the newspapers in their excitement
stated that these buildings burnt as quickly and as completely as the wooden ones, and people, the unthinking ones, generally decry against the "so-called fireproof construction," as they call it, because they
have discovered by this fire that they were wrong in their ideas that a fireproof building guaranteed immunity to even highly inflammable materials used in its decoration or stored within it. To say that the its decoration or stored within it. To say that the
structures actually burned is, of course, foolish and manifestly incorrect, even to the most ignorant, because they are still standing, and many of them in an cause they are still standing, and many of them in an
easily repairable condition. Take this Continental Trust, for instance; all the structural steel was in cased in tile, and not a bit of it is warped or out of level. The exposed metal portions are twisted into the frame, is intact. The structural conditions of all within the general scheme of our theories of fireproofing stood the awful test remarkably well. The Equitable building, which is, I imagine, an old building, and one in which, though tile was used, its application was
not made along scientific lines, makes a worse showing than any of the others. The soffits of its beams were exposed, the tile arches were segmental, the
haunches were not concreted, evidently to save money, and on top of the beams was a heavy two-inch plank floor covered with a finished dressed flooring. But
a portion of the webs of the beams being protected, the heat has twisted and curved these beams all out of shape, and necessarily distorted the columns, so that the building will undoubtedly have to be entirely re-
built. The structures of the Calvert building, the built. The structures of the Calvert building, the
Herald, the Union Trust, the Maryland Trust, are in air shape to be repaired as far as the structures go for the steelwork was fully protected by the tile fireproofing.

These skyscrapers were built to contend with ordinary conditions; for instance, if the fire had originated in any of them, it could not have gotten beyond subject to any such test from without. Even if such a possibility had been thought of, I venture to state that no one in Baltimore would have been willing to pay the increased cost that would have been entailed ad these buildings been erected to withstand any in the country where skyscrapers could be subjected to any such test. Those in New York are surrounded by a better class of buildings than generally obtained ington Post very aptly puts it that a "fireproof building is one that is fireproof itself and is surrounded by conditiof buildings." That, I grant, would be an idea for, but yet that definition of a fireproof structure is not essentially correct. Such another conflagration is possible in a city like Boston, or San Francisco, or rising from among shanties and the most inflammable of structures, and vast areas of these all about. In repairing these buildings in Baltimore and in building new ones of their class in this burnt district, no greater precautions need be taken, as far as structure is concerned, than we find in the best of the old ones, say the Continental Trust, for instance, because a better general class of buildings than the old wooden ones will be insisted upon by the authorities,
presumably, and in that case no such conflagration could again be possible in that district.

The general condition of the tile is good. Some dication of the disintegration of the materials. In some places the bottom web of the floor arches has been linocked off. It is hard to say what caused this exme a good deal washaps; but one case that worried floor arches in the vestibule of the Continental building. I was considerably relieved when told by one of erecting their work had knocked off all these webs for the purpose of facilitating the fastening of the marble! The superintendent who allowed anything of I was pleased, nevertheless, to find that this was no fire effect.

I have preached hard and earnestly and long against fire can get at it. The granite and stone in all the buildings, skyscrapers as well as the others, is utterly destroyed. Possibly it may be recut in places, but the shaling and splintering generally puts it beyond re-
demption. The brickwork stood remarkably well, and is simply another proof of our old theory that any material to successfully withstand fire must have gone
through as severe heat in its manufacture as it will through as severe heat in its

The decorative terra cotta here and there has been broken off, but on the whole it came out of the fray with flying colors. The less glazing there is to terra cotta, however, the better. The terra cotta people
should make their facework heavier and thicken their should make their facework heavier and thicken their
internal angles, so as to overcome the natural weakness internal angles, so as to overcome the natural weakness
of the material at its angular connections with the face of the material at its angular connections with the face
and they should encourage the use of porous nonglazed surfaces.

Some people say that this fire proves that an absolutely fireproof building is virtually an impossibility, or one that under such stress would afford protection
to its contents. It is only the unthinking who would make any such statement. The people who built the structures we have under discussion the Baltimore sky. scrapers, used fireproof methods only about their structural parts. In the finish and all else in these buildings the firetraps that stood all about them, and which have now disappeared from the face of the earth. In so far now disappeared from the face of the earth. In so far
as that fireproofing went it has been most eminently successful, and this terrible fire demonstrates its value more forcefully and potently than anything that has happened in the past twenty years.

Think of the test the steelwork was subjected to! nected metal, one very susceptible to variations in temperature, into a furnace where different parts of that metal would be subject at the same time to heats of $98 \mathrm{deg} ., 3,000 \mathrm{deg}$. and $400 \mathrm{deg}$., and remember that that metal was incased in sometimes not over two inches of tile, and that its parts were not warped, dis-
jointed, or otherwise damaged by that terrific heat-test. At some one time those tall buildings underwent about those variations of temperature. Realizing this, and
having those buildings standing before us in splendid having those buildings standing before us in splendid
proof of their stability, how can any one making claim proof of their stability, how can any one making claim
to the possession of even ordinary intelligence state to the possession of even ordinary
that "fireproofing" is not fireproof?

The great fire of Chicago in 1871 had for effect that, the country over, frame buildings were barred within
certain limits. This great fire of Baltimore is another certain limits. This great fire of Baltimore is another
step in the popular education, and will result in people doing more thorough fireproofing in their structures, and using less damageable materials in their exterior and interior decorations. But this education is slow-
awfully, pitifully slow-and enormously costly. It will take another such terrible experience to thoroughly impress the people with the fact that we so-called cranks on construction are right, and not making unreasonable demands in the line of improved methols
of building. We realize and appreciate the possibility of such things happening, but people call us "croakers" until the things we foretold would happen do happen then they come to us and tell us how clever we are, and ask our advice as to how they should build; and then they go off and erect the flimsiest of things the too complaisant laws will allow; because, forsooth, our Judging from money than they care to expend. laymen have experienced a change of heart, and are anxiously and insistently desirous of advice how to build well, rather than cheaply. But the desire will only last a f $\bullet$ w weeks, or months, perhaps. City law; safeguard-good laws and laws well enforced by com-
petent and zealous officers are the solution of the building probiem.

Some time ago, in these same columns and in the daily press, I made a statement that may be worth rewithin the week the quotation may not be without within the week, the quotation may not be without
point: "By years of persistent digging at the same subject we cranks on fireproofing have succeeded in 
getting people to build a large number of buildings whose structures are absolutely impervious to fire
[Baltimore must have proved that beyond a shadow of [Baltimore must have proved that beyond a shad

It has been hard work, and we have received many rebuffs, but it is now time to increase the scope of our efrorts a little, and try and inct pease the scope of our the ways of preventing fires within those fireproof structures and the destruction of any of their part years of persistent work we may get them to close up years of persistent work we may get them to close up
elevator and stair shafts in freproof partitions and doors. We may induce them to use freproo materials in the finish of their rooms, some form of cement or tile foors instead of wood, metal furnish
ings instead of wood again. . . . There is but one method of building a fireproof structure that is compatible with safety and our necessities, one that will neither burn nor be materially affected by any fire within or without. A structure whose frame
is of steel, thoroughly protected with cement and in cased entircly in hollow freproof tile, whose fioors are also of hollow fireproof tile arches, partitions of brick or hollow tile, and whose outer walls are of brick or terra cotta-not stone or granite, because both of these are actually dangerous in a fire. . . But the work
of education must be by easy stages, and we must give of education must be by easy stages, and we must give
these things to the people in small doses; to attempt to these things to the people in small doses; to attempt to get any one to build anywhere near perfectly at one
fell swoop would be an overdose, and you know what overdoses usually lead to." With all the lessons of the Baltimore fire now before me, I cannot think of any-
thing I would care to add to the above, written months ago, and preached for years back.

The perfectly fireproof building above alluded to, freproof in the sense that the average man interprets the term (in that no damage can be done to the building by fire, and that all he may put within that build ing is absolutely safe from external attack) is possible. I could build a structure, a skyscraper, upon which flict more than a few hundred dollars' worth of actua damage. But who in these times of careful calcula. tion of dividends and returns upon investments would pay for such a building? I would build its exterior trimmings, or hollow tile, and with molded brick more carefully made and burned than the usual commercial terra cotta; not a particle of marble, stone, or granite would be outside of that building. I would make the frame of steel, just as we do to-day and no in tile, a trifie heavier and thicker than is the average on the market to-day; the floors would be of hollow tile arches, covered with cement, or tile, or marble-no of metal covered with a heavy asbestos covering; all the windows and skylights I would doubly glaze with
wired glass: all the casings and finish would be of cement, and the doors of metal, and each story cut off from the other absolutely, no open elevator or stair wells. Such a building, with the ordinary precautions, and some water and other fre-fighting appliances within, would have withstood that fire in Baltimore unscathed, and would have protected all that might 3,000 deg. of heat developed at some points during that fire! But the exigencies of the time seem not to permit
so perfect a structure. Even fireproofing tile has been so perfect a structure. Even fireproofing tile has been
reduced in thickness to its minimum ability to withstand ordinary fire; the trade demands it; people will stand ordinary fre; the trade demands it; people will not pay for more tonnage. Everything that goes into a building has to be pared down and shaved, particu-
larly in the structure, so that there may be profit in larly in the structure, so that there may be profit in
renting the building. If there is anything upon which renting the building. If there is anything upon which
money is spent at all lavishly, it must be fine carvings on the outside, and rare marbles, and polished woods on the outside, and rare marbles, and polished wo ansent
inside, things that catch the eye and give an apparent value to property. Natural enough, but lamentable
just the same, and in Baltimore's case, at least, exjust the same, and in Baltimor
ceedingly expensive ultimately.

Architects are too prone to take certain standards Architects are too prone to take certain stanlards
of make of any material and use it everywhere regardof make of any material and use it everywhere regard-
less of varying conditions. Now, as I said before, in the upbuilding of this district of Baltimore, or in building in sections in other cities that are pretty well building in sections in other cities that are pretty well
filled with good buildings, mostly fireproof structures, nothing more is needed than was used in Baltimore's slysscrapers we now have under consideration. But in crowded districts of comparatively flimsy structures, in just such a place as were those very build-
ings in Baltimore, and in other old cities where like conditions exist, or in New Orleans, or San Francisco. or Boston, or in some parts of New York, or in any other extra-ha\%arlous positions, in Heaven's name why not take extraordinary precautions, and use a heavier
and thicker tile in floors and in incasing the steel; and thicker tile in floors and in incasing the steel;
wired glass on the exposed fronts, and at least metal frames at such exposed windows; why should not every precaution be taken that experience teaches us
is necessary, or that even tends to minimize the dam. is necessary, or that even tends to minimize the dam-
age that could be done by just such another conflagration?

A careful examination, such as I have made of that entire district, was immensely interesting and certainly helpful in developing any Sherlock Holmes propensities one might have. So many seemingly inex-
plicable things happened, what might be-termed freaks of fire, and yet, if one knew all the circumstances, and
put ones and twos enough together, most of those freaks could be readily explained. The escape of cer-
tain small buildings from almost any damage, the tain small buildings from almost any damage, the perable barrier presented itself, the skipping of flames over large areas seemingly drawn to some particula point of attack, high up in the air and not along the prevailing direction of the wind, while another fire
was more slowly eating into the very foundations of was more slowly eating into the very foundations of ruins, setting at naught the very frst principles of statics-all of these strange things were, as I say,
fascinatingly interesting, and will be food for thought and study and experiment and much theorizing on the part of those scientifically inclined, and will ultimately, of course, prove of considerable benefit to the
world. I saw in one place three brick arches resting world. I saw in one place three brick arches resting
on columns of granite that had been completely eaten on columns of granite that had been completely eaten
away, yet the arches stood absolutely intact and carrying a considerable weight above them and without a particle of support under the two central skewbacks;
these arches apparently reflecting into one structural these arches apparently reflecting into one structural
supporting arc sustaining the pendative load at the supporting arc sustaining the pendative lo
two intermediate points by mere adhesion.

A considerable portion of the Custom House now under construction will have to be torn down. In one place there is a granite cornice temporarily covered
with planks; the planking is not even scorched, while with planks; the planking is not even scorched, while
the granite underneath it is shaled off, cracked, and badly scaled. Mast of the damage was by heat unaccompanied by flames. : Some of the ironwork inside not yet protected with fireproofing will also have to be taken down. The handsome marble court house, recently completed, was somewhat damaged externally. It was just outside of the zone of fire, but received
a hot enough blast to damage its stonework to the a hot enough blast to

In Baltimore, as everywhere else, there was and is some lamentable negligence in the way of superintendence, which simply goes to prove, as I have always in ended, the folly of using any material whose safety perfect tinental building the bricliwork is of course carried from story to story. I noted great patches on the side walls some thirty or more feet in length by the of brick had been detached and had fallen off, showing that in all that extent of wall there was not a particle of bond, either of metal or of brick, between that course and the backing. Such work as that and the other and cut everything to pieces, in order to install their work with greater ease, is certainly shameful, and shows culpable and criminal neglige

In the freproof buildings, most of the partitions were in most excellent shape, but I noticed in one that whole sections of partition were on the foor, in connected condition, and not in the shape they would have been had they fallen there. It seemed a case of their being thrown down by some terrific force. The fire could have had no such effect unless
the draft was even greater than the maximum of my calculation-the rate of 180 miles an hour was un loubtedly reached - and it certainly was not the work of the fremen. Insistent investigation showed me that they had tried to cut off the fre near that point with dynamite, and it was these series of explosions so near that had thrown down section after section of partitions in such peculiar shape and manner. A considerable part of the front wall of the Union
Trust building will have to be talken down. The steel frame in that outer wall was not carefully enough protected, so that the heat has warped it, and as a protected, so that the heat has warped it, and as a shapes. It is in a dangerous condition. The interior framing is, I believe, in perfect condition.

It is to be regretted that there were no important or tall concrete constructions in that zone of fre. Had or tall concrete constructions in that zone of fre. Had
there been, we certainly would have had a good basis of the comparative value of that mode of construction. of the comparative value of that mode of construction.
There was but one concrete building that I could find There was but one concrete building that I could find
There may have been others that were destroyed, but The one I examined was about 30 by 75 feet, four stories high, built on the Hennebique system, and it stories high, built on the Hennebique system, and it seemed fairly intact, except in one or two of its con-
crete beams. The condition of the iron front show crete beams. The condition of the iron front shows dent that there was comparatively little combustible pipes are in fairly good shape. That the floors stoo up while the wooden floors in the adjacent building were destroyed proves that the system is certainly better than wood-if the building can be completed without collapsing; but that this was a test of what it would do in a tall construction or in a more exposed place is stretching the point to its utmost elasticity. other low points, were comparatively quickly over and not of the most intense, is shown by the condition the metal in this building, and by the fact that directly across the street, in one of the fireproof skyscraper the Maryland Trust building, for the same height up, four or five stories, the decorative plastering on the
ceilings is not even charred, and some of the light fixtures are hanging intact. The fire seems to have swept by at frightful velocity, quickly devouring al woodwork and anything combustible, but leaving even
the concrete and plastering in pretty gool shape The plastering and everything else in the Maryland
building above the fifth floor show that the heat was vastly more intense above the line of that concrete building. I should imagine that the heat at that
one point was not over 600 deg.; at the seventh and one point was not over $600 \mathrm{deg}$; at the seventh and
eighth floors in 'some of these skyscraper buildings, it must have reached nearly 3,000 deg., because I found in one place a safe that was not only warped all out of shape, but one of its angles, that nearest the window, was fused, molten down, and had trickled much as twelfth and topmost stories I noted that some brass had but begun to fuse alongside of some cast iron that was badly warped, but had not nearly reached the fusing point. The heat there was certainly not over 2,000 deg., while in other places on the top of
three and four-storied buildings I found lead that three and four-storied buildings I found lead that showed no signs of fusing, all of which would indicate
that the heat was most intense at the point where the that the heat was most intense at the point where the
frst blast of fame struck those tall buildings. The first blast of fame struck those tall buildings. The
resulting variation of temperature in the height of resulting variation of temperature in the height of these skyscrapers was enough, one would think, to dis-
tort the steel whatever it might be incased in or protort the steel
tected with.

The owners of these skyscrapers may feel somewhat aggrieved that their buildings, being called "fireproof," did not meet the popular interpretation of that term, and safeguard not only the structural parts, but all the goods and inflammable materials within and about the buildings. And they may, and with justice, feel abused in that their architects advised the use of granite or stone exterior walls, when they ought to have known that a much lesser fre even would play havoc with those materials; but after viewing the absolute destruction of everything else in their vicinity, and unexpected test their buildings passed through, something that neither they nor their architects ever dreamed of or deemed possible, and that we have been laughed at every time we suggested, they must appreciate that amid all that desolation they alone have any cause for thankfulness, for their buildings may be repaired and refitted ready for tenants long before much smaller buildings.
much

Much is to be learned from that fire in the way of improving methods to fight fire, bettering water systems, and all that sort of thing; but as far as the do a general good in that it will open the eyes of the people to the advantages of building as we suggest, using the materials we advise and taking the preI frankly confess, it neither revealed, demonstrated, nor proved anything engineers and fireproof specialists did not know before and have so persistently advocated heretofore. With the results of that fire clearly laid out before me, I would not change in the zlightest I change the stanclard patterns for fireproofing fioors, partitions, column coverings, etc., except to slightly ncrease their thicknesses for extraordinarily hazardcould I alvise anything better in interior finish, in the glazing of windows, and the hundred other minutiæ and detail of building, than I have advised and used prior to that fire. The trouble is not with the en gineers, the teachers, but with the refractory pupils,
upon whom even such a lesson is liable to make small impression. and practised have been applied in the structures that have so successfully passecl through the test of have so successf ully passecl through the test of
the Baltimore fre, are we fully vindicated in ow bethe Baltimore fire, are we fully vindicated in $0^{\prime \prime}$ be-
liefs, and have we just cause for jubilation; for we may now demonstrate the soundness of our contention, may now demonstrate the soundness of our contention,
when questioned by the sleptical or doubting ones, by when questioned by the slieptical or doubting ones, by
merely pointing to the steel, tile-incased structures merely pointing to the steel, tile-incased structures
that resisted and were the victors in the mighty battle that was waged against them at Baltimore February that was
$7,1904$.

THE WRIGHT EXPERIMENTS IN FLYING.

Ix October last we resumed the trials on the Kill Devil practice ground with the machine which we had used during the previous year, and succeeded in making flights in which the operator remained in the air over a minute, at one time being suspended 1 minute our power machine was under construction. mensions it measures a little over 40 feet from tip to tip of the wings, of which there are a pair. Its tip of the wings, of which there are a pair. Its
length fore and aft, to use a nautical phrase, is about length fore and aft, to use a nautical phrase, is about
20 feet, and the weight, including that of the operator, as well as the engine and other machinery, is slightly over 700 pounds. We designed the machine to be over 700 pounds. We designed the machine to be
driven by a pair of aerial screw propellers placed just driven by a pair of aerial screw propellers placed just
behind the main wings. One of the propellers was set to revolve vertically and intended to give a forset to revolve vertically and intended to give a for-
ward motion, while the other underneath the machine
and revolving horizontally, was to assist in sustaining it in the air.

We decided to use a gasoline motor for power, and We decided to use a gasoline motor for power, and
constructed one of the four-cycle type, which, revolving constructed one of the four-cycle type, which, revolving
at a speed of 1,200 revolutions a minute, would develop 16 brake horse power. It was provided with cylinders of 4-inch diameter and having a 4 -inch stroke and intended to consume between 9 and 10 pounds of gasoline an hour. The weight of the engine includin We had is 152 pound.

We had amount of mechan nower would be sufficient to maintain the machine in the air, as well as to propel it, the calculations being
the result of gliding experiments, which showed that 